\title{
Left ventricular structure in relation to the human $S A H$ gene in the European Project on Genes in Hypertension
}

\author{
Yu Jin ${ }^{1}$, Tatiana Kuznetsova ${ }^{1}$, Valérie Tikhonoff ${ }^{2}$, Lutgarde Thijs ${ }^{1}$, Sandra Hasenkamp ${ }^{3}$, Veronika Bäumer ${ }^{3}$, \\ Katarzyna Stolarz-Skrzypek ${ }^{4}$, Andrew Ryabikov ${ }^{5}$, Tom Richart ${ }^{1,6}$, Sofia Malyutina ${ }^{5}$, Yuri Nikitin ${ }^{5}$, \\ Edoardo Casiglia $^{2}$, Kalina Kawecka-Jaszcz ${ }^{4}$, Agnieszka Olszanecka ${ }^{4}$, Stefan-Martin Brand-Herrmann ${ }^{7}$, \\ Eva Brand ${ }^{3}$, Robert Fagard ${ }^{1}$ and Jan A Staessen ${ }^{1,6}$, for the European Project on Genes in Hypertension \\ (EPOGH) Investigators
}

\begin{abstract}
Earlier studies showed association of the human SAH (Spontaneously hypertensive rat-clone A-Hypertension associated) gene with hypertension and obesity. Left ventricular mass index (LVMI) increases with blood pressure and body mass index. In a family-based population study (54.5\% women; mean age, 43.1 years), we measured LVMI, mean wall thickness (MWT) and the left ventricular internal diameter (LVID) at end-diastole in 699 non-Slavic and 493 Slavic participants. In multivariable-adjusted analyses, we investigated phenotype-genotype associations ( $\mathrm{SAH}$ G-1606A and $-962 \mathrm{ins} / \mathrm{del}$ polymorphisms), while accounting for confounders and relatedness. Non-Slavic $-1606 \mathrm{GG}$ homozygotes had a slightly greater LVID than $-1606 \mathrm{~A}$ allele carriers ( 48.6 vs. $48.0 \mathrm{~mm} ; P=0.08$ ). However, the between-family component of the variance in LVID was significant $(P=0.005)$, suggesting that population stratification might explain the latter finding. Non-Slavic-962del carriers had higher LVMI (91.1 vs. $88.5 \mathrm{~g} \mathrm{~m}^{-2} ; P=0.03$ ) and MWT (9.61 vs. $\left.9.44 \mathrm{~mm} ; P=0.03\right)$ than -962 ins homozygotes. Transmission of the $-962 \mathrm{del}$ to non-Slavic offspring was also associated with higher MWT $(P=0.03)$. In Slavic participants, in the absence of population stratification $(P \geqslant 0.69),-1606 G G$ homozygotes had lower LVMI (96.5 vs. 102.3 $\left.\mathrm{g} \mathrm{m}^{-2} ; P=0.004\right)$ and lower MWT (10.1 vs. $10.5 \mathrm{~mm} ; P=0.003$ ) than $-1606 \mathrm{~A}$ carriers. Sensitivity analyses showed that the latter associations were confined to founders. Transmission of the $-962 \mathrm{del}$ allele to Slavic offspring was associated with lower MWT $(P=0.007)$. In conclusion, LVMI and MWT, two phenotypes that are jointly influenced by blood pressure and obesity, might be related to variation in the human SAH gene.
\end{abstract}

Hypertension Research (2009) 32, 145-151; doi:10.1038/hr.2008.30; published online 16 January 2009

Keywords: left ventricle; left ventricular mass index; mean wall thickness; SAH gene; population science

\section{INTRODUCTION}

The expression of $S A H$ (Spontaneously hypertensive rat-clone AHypertension-associated) gene is markedly higher in the kidneys of spontaneously hypertensive rats compared with normotensive WistarKyoto control rats. ${ }^{1}$ In rats, $\mathrm{SAH}$ is expressed mainly in the proximal renal tubules. ${ }^{2}$ The human $S A H$ gene is located on chromosome $16 \mathrm{p} 13.11 .^{3}$ Several earlier studies suggested association of the human $S A H$ gene with hypertension and related metabolic phenotypes, such as obesity, ${ }^{4}$ hypercholesterolemia ${ }^{5}$ and hypertriglyceridemia. ${ }^{6}$ However, we recently analyzed blood pressure, measures of obesity, serum lipids and blood glucose as continuous phenotypes in 2603 relatives from 560 families and 31 unrelated subjects randomly recruited from six populations in the framework of the European Project on Genes in Hypertension (EPOCH). We genotyped our study population for SAH G-1606A and $-962 \mathrm{ins} / \mathrm{del}$. In spite of sufficient statistical power, none of the phenotype-genotype associations approached statistical significance. $^{7}$

Left ventricular mass index (LVMI) increases with blood pressure and body mass index. ${ }^{8}$ This phenotype might therefore more readily pick up association with variation in the $S A H$ gene. In this study, we explored possible association between left ventricular structure and the G-1606A and -962ins/del polymorphisms in the human SAH gene.

${ }^{1}$ Studies Coordinating Centre, Division of Hypertension and Cardiovascular Research, Department of Cardiovascular Diseases, University of Leuven, Leuven, Belgium; ${ }^{2}$ Department of Clinical and Experimental Medicine, University of Padova, Padova, Italy; ${ }^{3}$ Department of Internal Medicine D, Nephrology and Hypertension, University of Münster, Münster, Germany; ${ }^{4}$ First Department of Cardiology and Hypertension, Jagiellonian University Medical College, Kraków, Poland; ${ }^{5}$ Institute of Internal Medicine, Novosibirsk, the Russian Federation; ${ }^{6}$ Department of Epidemiology, Maastricht University, Maastricht, the Netherlands and ${ }^{7}$ Department of Molecular Genetics of Cardiovascular Disease, The Leibniz-Institute for Arteriosclerosis Research, University of Münster, Münster, Germany

Correspondence: Dr JA Staessen, Studies Coordinating Centre, Division of Hypertension and Cardiovascular Research, Department of Cardiovascular Diseases, University of Leuven, Campus Gasthuisberg, Herestraat 49, Box 702, Leuven B-3000, Belgium.

E-mails: jan.staessen@med.kuleuven.be or ja.staessen@epid.unimaas.nl

Received 10 September 2008; revised 22 November 2008; accepted 28 November 2008; published online 16 January 2009 


\section{METHODS}

\section{Study population}

We conducted the European Project on Genes in Hypertension according to the principles outlined in the Helsinki declaration for investigations in human subjects. ${ }^{9}$ The Ethics Committee of each institution approved the study. In seven European countries, investigators randomly enrolled nuclear and extended families of White Caucasian ethnicity. Four centers took part in the substudy on echocardiography ${ }^{10,11}$ and together enrolled 1522 subjects in Kraków (Poland; $n=325)$, Novosibirsk (Russian Federation; $n=301$ ), Mirano (Italy; $n=345$ ) and Hechtel-Eksel (Belgium; $n=551$ ). The overall response rate was $67.8 \%$. All participants gave informed written consent. We excluded 330 subjects from analysis, (1) because ECGs were either unavailable $(n=96)$ or of insufficient quality $(n=52)$, (2) because participants had left ventricular dysfunction due to myocardial infarction or valvular disorders $(n=52),(3)$ because of lack of measurements required for our analysis $(n=58)$, (4) because DNA failed to amplify ( $n=63$ ) (5) or because of inconsistency in Mendelian segregation $(n=9)$. Thus, the number of subjects statistically analyzed totaled 1192

\section{Echocardiographic measurements}

In each center, one highly experienced observer performed all ECGs, using a commercially available device equipped with a $3.5-\mathrm{MHz}$ transducer. ${ }^{10,11}$ With subjects in left decubitus and breathing normally, the observers obtained Mmode echocardiograms of the left ventricle from the parasternal long-axis view under control of the two-dimensional image. They positioned the ultrasound beam just below the mitral valve at the level of the posterior chordae tendineae. The echocardiographic examinations were recorded on videotape and analyzed offline. The observers measured left ventricular internal diameter (LVID) and interventricular septal and posterior wall thickness at end-diastole, according to the recommendations of the American Society of Echocardiography. ${ }^{12}$ Mean wall thickness (MWT) was half of the sum of the interventricular septal and posterior wall thickness at end-diastole. Left ventricular end-diastolic dimensions were used to compute left ventricular mass by an anatomically validated formula. ${ }^{12}$ LVMI was left ventricular mass divided by body surface area, calculated as body weight 0.425 (in $\mathrm{kg}$ ) $\times$ body height 0.725 (in $\mathrm{cm}) \times 0.007184$. For statistical analysis, the measurements of three cardiac cycles were averaged.

\section{Other measurements}

With the subjects seated for at least $5 \mathrm{~min}$, trained nurses obtained five consecutive blood pressure readings at the examination center. The blood pressure phenotype was the average of these five readings. Hypertension was a blood pressure of $\geqslant 140 \mathrm{~mm} \mathrm{Hg}$ systolic or $\geqslant 90 \mathrm{~mm} \mathrm{Hg}$ diastolic or the use of blood pressure lowering medications. Body mass index was weight in kilograms divided by the square of height in meters. We used a standardized questionnaire to collect information on each subject's medical history, smoking and drinking habits and intake of medications. The participants collected a 24-h urine sample in a wide-neck plastic container for the measurement of sodium, potassium and creatinine. If urinary volume or creatinine excretion were outside published limits, ${ }^{13}$ the urinary measurements were considered to be missing and subjects were excluded from analysis.

\section{Determination of genotypes}

We extracted genomic DNA from WBCs, using the standard kits (Qiagen, Hilden, Germany). For genotyping, we used restriction fragment length polymorphism analysis of the respective PCR products at the frequent polymorphic loci G-1606A (restriction enzyme KspAI) and -962ins/del (XapI). Because the $C-1808 T$ was completely associated with $G-1606 A,{ }^{14}$ we did not genotype for this variant.

Using the published sequence of human $S A H$ gene (accession number AC004381.1), primers were designed to amplify both fragments covering the appropriate SAH polymorphic sites. The PCR amplification was carried out in a $20-\mu$ l volume, containing $5 \mathrm{ng}$ genomic DNA, 10 and $25 \mathrm{pmoll}^{-1}$ of each primer (for both fragments, respectively), $2.5 \mathrm{mmoll}^{-1} \mathrm{MgCl}_{2}, 200 \mathrm{moll}^{-1}$ of each dNTP, $5 \mathrm{mmoll}^{-1}$ betaine and $1 \mathrm{U}$ AmpliTaq polymerase (Rapidozym, Berlin, Germany). The PCR was performed initially for $3 \mathrm{~min}$ at $94^{\circ} \mathrm{C}$ and followed by 35 cycles, each with $45 \mathrm{~s}$ at $94^{\circ} \mathrm{C}, 45 \mathrm{~s}$ at 54 and $56^{\circ} \mathrm{C}$ (depending on primer sequence), $60 \mathrm{~s}$ at $72{ }^{\circ} \mathrm{C}$ and final elongation of $10 \mathrm{~min}$ at $72{ }^{\circ} \mathrm{C}$.

In the presence of the $-1606 \mathrm{~A}$ allele, the PCR product ( $221 \mathrm{bp}$ ) was digested by KspAI into two fragments of 191 and $30 \mathrm{bp}$ in length ( $-1606 \mathrm{G}$ undigested). In the presence of the $-962 \mathrm{del}$ allele, the PCR product ( $339 \mathrm{bp}$ ) was digested by XapI into three fragments of 180, 93 and 66 bp in length. For -962ins, the PCR product (344 bp) was digested into four fragments of 180, 82, 66 and $16 \mathrm{bp}$ in length, visualized on ethidium bromide-stained 3\% agarose gels (primer sequences and digestion conditions are available upon request).

\section{Statistical analysis}

For database management and statistical analysis, we used SAS software, version 9.1.3 (SAS Institute, Cary, NC, USA). We compared means and proportions, using the large-sample $z$-test and the $\chi^{2}$-statistic, respectively. Our statistical methods also included single and multiple linear regressions. We included in our models covariables with known physiological relevance to the left ventricular phenotypes under study, using stepwise multiple regressions with the significance level for independent variables to enter and stay in the model set at 0.15 .

We performed both population-based and family-based analyses. As in earlier analyses, ${ }^{7}$ we combined the least frequent homozygous group with the heterozygous subjects. We tested linkage disequilibrium, using the SAS procedure PROC ALLELE. We applied a generalization of the standard linear model, as implemented in the PROC MIXED procedure of the SAS package, to test the associations between phenotypes and single-nucleotide polymorphisms, while accounting for relatedness and adjusting for covariables. We tested for heterogeneity, using appropriate interaction terms with the genotypes.

In the family-based analysis, we performed transmission disequilibrium tests for quantitative traits (QTDT). We partitioned the phenotypic variance into between and within family components, using the orthogonal model ${ }^{15}$ as implemented in Abecasis's QTDT software (version 2.6.0, available at http://www.sph.umich.edu/ csg/abecasis/QTDT). The within-family component of phenotypic variance reflects the genetic effect and is robust to population stratification.

\section{RESULTS}

\section{Characteristics of the participants}

The study population consisted of 1014 relatives from 252 families and 178 unrelated subjects. There was significant heterogeneity between the non-Slavic (Mirano and Hechtel-Eksel) and Slavic (Kraków and Novosibirsk) participants in the association of MWT $(P=0.065)$ and LVMI $(P=0.012)$ with the $S A H G-1606 A$ polymorphism. Moreover, non-Slavic and Slavic participants had different $(P<0.0001)$ age $(47.6$ vs. 36.7 years), waist-to-hip ratio (0.86 vs. 0.83$)$, pulse rate $(66.0 v s$. 70.7 beats per minute), urinary excretion of sodium (175.3 vs. $\left.230.0 \mathrm{mmol} \mathrm{day}^{-1}\right)$ and potassium $\left(69.4\right.$ vs. $\left.62.1 \mathrm{mmol} \mathrm{day}^{-1}\right)$, and LVMI (87.5 vs. $94.9 \mathrm{~g} \mathrm{~m}^{-2}$ ). For these reasons, in keeping with earlier reports, ${ }^{10}$ we stratified all analyses according to ethnicity. Tables 1 and 2 list the subjects' characteristics by $S A H$ genotypes for non-Slavic and Slavic participants, respectively. In both non-Slavic and Slavic subjects, LVMI increased with age (Figure 1).

\section{Genotype frequencies}

Table 3 reports the genotype and allele frequencies of the two $S A H$ polymorphisms. The $-1606 \mathrm{~A}$ allele frequencies were 11.7 and $12.1 \%$ in non-Slavic and Slavic participants, respectively $(P$ for difference between ethnicities, 0.80). The frequency of the $-962 \mathrm{del}$ allele was higher in non-Slavic than Slavic subjects (30.4 vs. $26.0 \%$; $P=0.02$ ).

In all four centers, the frequencies of the $G-1606 \mathrm{~A}$ and $-962 \mathrm{ins} / \mathrm{del}$ genotypes were complied with Hardy-Weinberg proportions $(0.20<P<0.59$ and $0.14<P<0.98$, respectively), except for the $G-1606 A$ genotypes in Kraków $(P=0.02)$. The two $S A H$ polymorphisms were in complete linkage disequilibrium. Lewontin's disequilibrium coefficient D' was $1.00(P<0.0001)$. 
Table 1 Characteristics of participants by the $G-1606 A$ genotypes

\begin{tabular}{|c|c|c|c|c|}
\hline \multirow{2}{*}{$\begin{array}{l}\text { Characteristic } \\
\text { G-1606A }\end{array}$} & \multicolumn{2}{|c|}{ Non-slavic } & \multicolumn{2}{|c|}{ Slavic } \\
\hline & $A A+G A(\mathrm{n}=158)$ & $G G(\mathrm{n}=541)$ & $A A+G A(n=115)$ & $G G(\mathrm{n}=378)$ \\
\hline Women, $n(\%)$ & $86(54.4)$ & $282(52.1)$ & $53(46.0)$ & $229(60.6)^{*}$ \\
\hline Age (years) & $47.9 \pm 15.6$ & $47.5 \pm 14.6$ & $35.2 \pm 13.5$ & $37.1 \pm 14.3$ \\
\hline Body height $(\mathrm{cm})$ & $168.4 \pm 9.1$ & $168.2 \pm 9.5$ & $170.4 \pm 8.6$ & $168.1 \pm 9.2$ \\
\hline Body mass index $\left(\mathrm{kg} \mathrm{m}^{-2}\right)$ & $25.8 \pm 3.8$ & $25.7 \pm 4.0$ & $25.0 \pm 4.8$ & $25.5 \pm 5.1$ \\
\hline Pulse rate (beats min $^{-1}$ ) & $66.4 \pm 9.5$ & $65.8 \pm 10.3$ & $70.1 \pm 9.2$ & $70.9 \pm 9.8$ \\
\hline Systolic pressure $(\mathrm{mm} \mathrm{Hg})$ & $126.3 \pm 15.5$ & $126.5 \pm 17.1$ & $122.9 \pm 16.3$ & $125.6 \pm 21.0$ \\
\hline Diastolic pressure $(\mathrm{mm} \mathrm{Hg})$ & $78.7 \pm 9.2$ & $79.5 \pm 10.0$ & $80.1 \pm 10.5$ & $80.8 \pm 12.9$ \\
\hline \multicolumn{5}{|l|}{ Questionnaire data } \\
\hline \multicolumn{5}{|l|}{ 24-h urinary measurements } \\
\hline Volume $\left(\right.$ day $\left.^{-1}\right)$ & $1.76 \pm 0.70$ & $1.67 \pm 0.72$ & $1.47 \pm 0.50$ & $1.37 \pm 0.50$ \\
\hline Creatinine $\left(\mathrm{mmol} \mathrm{day}^{-1}\right)$ & $10.9 \pm 3.9$ & $11.4 \pm 4.1$ & $12.2 \pm 3.9$ & $11.4 \pm 3.9$ \\
\hline Sodium $\left(m m o l\right.$ day $\left.^{-1}\right)$ & $182.4 \pm 73.6$ & $173.3 \pm 69.3$ & $260.6 \pm 113.6$ & $220.7 \pm 88.7^{\dagger}$ \\
\hline Potassium (mmol day ${ }^{-1}$ ) & $71.0 \pm 28.8$ & $68.9 \pm 26.0$ & $67.2 \pm 24.9$ & $60.5 \pm 23.1^{*}$ \\
\hline
\end{tabular}

Data are mean \pm s.d. or number of subjects $(\%)$. Blood pressure was the average of five readings. Significance of the difference between genotypes: ${ }^{*} P \leqslant 0.01 ;{ }^{\dagger} P \leqslant 0.001$.

Table 2 Characteristics of participants by the -962ins/del genotypes

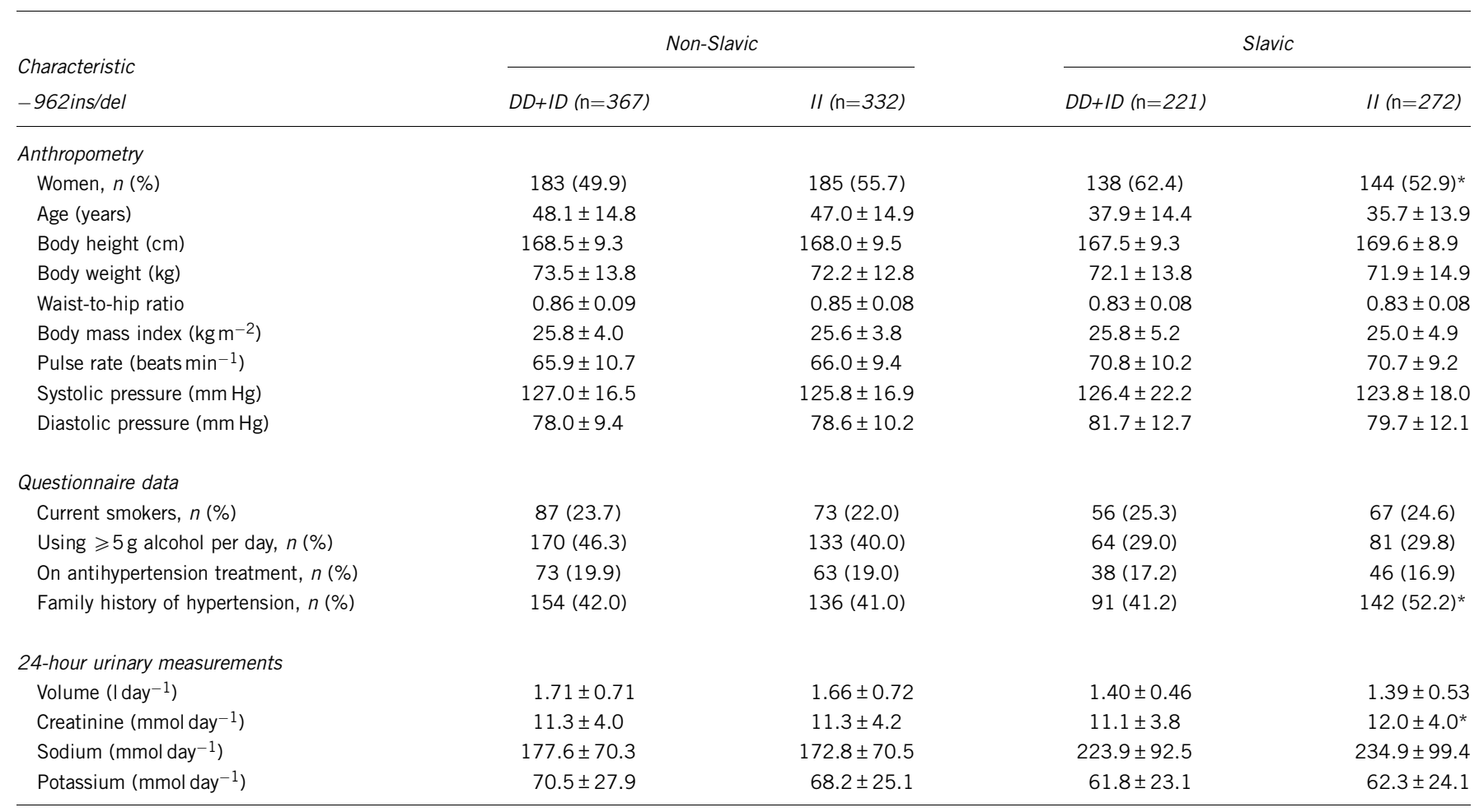

Data are mean \pm s.d. or number of subjects (\%). Blood pressure was the average of five readings.

Significance of the difference between genotypes: ${ }^{*} P \leqslant 0.05$. 


\section{Population-based association study}

As in earlier analyses, ${ }^{10,11}$ we adjusted the left ventricular phenotypes for center, sex, age, systolic blood pressure, body weight and height, waist-to-hip ratio, pulse rate, use of antihypertensive drugs and lifestyle factors, including smoking and alcohol consumption in excess of $5 \mathrm{~g}$ per day. Models with LVMI as the dependent variable were not adjusted for body weight and body height. With these adjustments applied, in both non-Slavic and Slavic participants, we did not detect any heterogeneity between single centers in the relations between the left ventricular phenotypes and the $G-1606 \mathrm{~A}$ and $-962 \mathrm{ins} / \mathrm{del}$ polymorphisms.

In non-Slavic participants (Table 4), the multivariable-adjusted mixed model showed a slightly greater $(P=0.080)$ LVID in $-1606 G G$ homozygotes than in $-1606 \mathrm{~A}$ allele carriers. Furthermore, non-Slavic -962del carriers, compared with -962ins homozygotes, had higher LVMI $(P=0.03)$ and MWT $(P=0.03)$. In Slavic participants (Table 4$),-1606 A$ allele carriers had higher LVMI $(P=0.004)$ and higher MWT $(P=0.003)$ than $-1606 G G$ homozygotes.

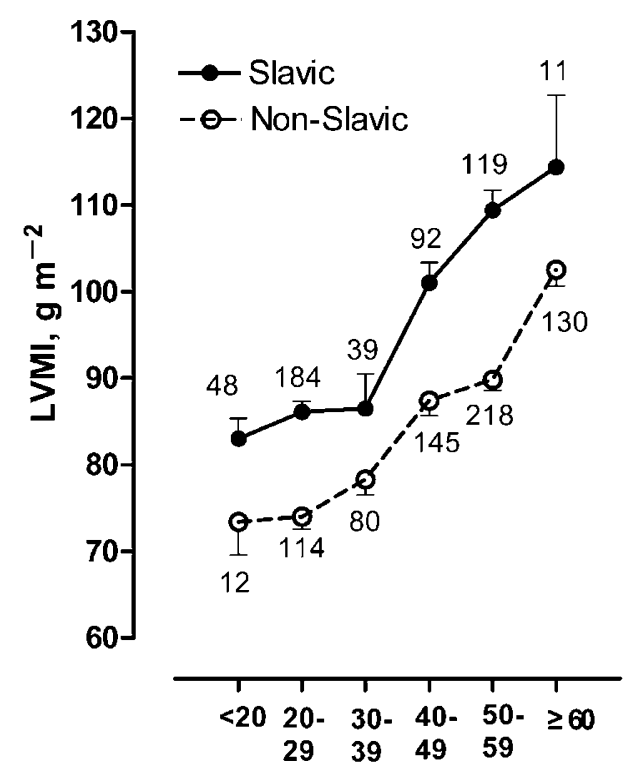

Age, years

Figure 1 Left ventricular mass index (LVMI) by ethnicity and age. Values are means \pm standard errors. Numbers are counts of subjects included in each plotted point.
Family-based association study

Our family-based analyses included 651 offspring and 541 parents (including unrelated subjects). We adjusted the QTDT analyses, as described above. Table 5 lists the between-family and within-family effect sizes associated with the $G-1606 A$ and $-962 i n s / d e l$ polymorphisms. In non-Slavic participants, the between-family component of variance in LVID was significant for the $G-1606$ A polymorphisms $(P=0.005)$, and transmission of the $-962 \mathrm{del}$ to informative offspring was associated with higher MWT $(P=0.03)$. In Slavic subjects, the between-family component of variance in MWT was borderline significant $(P=0.055)$ for the -962 ins/del polymorphism. Transmis-

Table 4 Left ventricular phenotypes in relation with variation in the $S A H$ gene

\begin{tabular}{|c|c|c|c|}
\hline \multicolumn{4}{|c|}{ Non-Slavic } \\
\hline$G-1606 A$ & $A A+G A(\mathrm{n}=158)$ & $G G(n=541)$ & P-values \\
\hline LVMI $\left(\mathrm{g} \mathrm{m}^{-2}\right)$ & $88.1 \pm 1.5$ & $90.4 \pm 1.1$ & 0.12 \\
\hline LVID (mm) & $48.0 \pm 0.4$ & $48.6 \pm 0.3$ & 0.08 \\
\hline MWT (mm) & $9.49 \pm 0.11$ & $9.54 \pm 0.08$ & 0.63 \\
\hline -962ins/del & $D D+I D(\mathrm{n}=367)$ & $/ /(\mathrm{n}=332)$ & P-values \\
\hline LVMI $\left(\mathrm{g} \mathrm{m}^{-2}\right)$ & $91.1 \pm 1.2$ & $88.5 \pm 1.2$ & 0.03 \\
\hline LVID (mm) & $48.4 \pm 0.3$ & $48.5 \pm 0.3$ & 0.83 \\
\hline MWT (mm) & $9.61 \pm 0.08$ & $9.44 \pm 0.08$ & 0.03 \\
\hline \multicolumn{4}{|c|}{ Slavic } \\
\hline$G-1606 A$ & $A A+G A(\mathrm{n}=115)$ & $G G(n=378)$ & P-values \\
\hline LVMI $\left(\mathrm{g} \mathrm{m}^{-2}\right)$ & $102.3 \pm 2.0$ & $96.5 \pm 1.4$ & 0.004 \\
\hline LVID (mm) & $48.6 \pm 0.4$ & $48.3 \pm 0.3$ & 0.45 \\
\hline MWT (mm) & $10.5 \pm 0.13$ & $10.1 \pm 0.09$ & 0.003 \\
\hline -962ins/del & $D D+I D(\mathrm{n}=221)$ & $/ /(n=272)$ & P-values \\
\hline LVMI $\left(\mathrm{g} \mathrm{m}^{-2}\right)$ & $97.6 \pm 1.7$ & $98.2 \pm 1.5$ & 0.70 \\
\hline LVID (mm) & $48.5 \pm 0.3$ & $48.2 \pm 0.3$ & 0.49 \\
\hline MWT (mm) & $10.1 \pm 0.11$ & $10.2 \pm 0.10$ & 0.20 \\
\hline
\end{tabular}

Data are mean \pm s.e. LVMI, LVID and MWT indicate left ventricular mass index, left ventricular end-diastolic internal diameter and mean wall thickness, respectively. $P$-values refer to the difference between genotypes.

Table 3 Frequencies of genotypes and alleles

\begin{tabular}{|c|c|c|c|c|c|}
\hline \multirow{2}{*}{ Variable } & \multicolumn{3}{|c|}{ Genotypes } & \multicolumn{2}{|c|}{ Alleles } \\
\hline & $G G$ & $G A$ & $A A$ & $G$ & $A$ \\
\hline \multicolumn{6}{|l|}{$G-1606 A$} \\
\hline Non-Slavic $(n=699)$ & $541(77.4 \%)$ & $152(21.8 \%)$ & $6(0.86 \%)$ & $1234(88.3 \%)$ & $164(11.7 \%)$ \\
\hline \multirow[t]{2}{*}{ Slavic ( $n=493)$} & $378(76.7 \%)$ & $111(22.5 \%)$ & $4(0.80 \%)$ & $867(87.9 \%)$ & $119(12.1 \%)$ \\
\hline & $D D$ & $D I$ & II & $D$ & 1 \\
\hline \multicolumn{6}{|l|}{-962ins/del } \\
\hline Non-Slavic $(n=699)$ & $58(8.3 \%)$ & $309(44.2 \%)$ & $332(47.5 \%)$ & 425 (30.4\%) & $973(69.6 \%)$ \\
\hline Slavic ( $n=493)$ & $35(7.1 \%)$ & $186(37.7 \%)$ & $272(55.2 \%)$ & 256 (26.0\%) & $730(74.0 \%)$ \\
\hline
\end{tabular}

Values indicate number of subjects or alleles (\%). 
Table 5 Between- and within-family effect sizes associated with transmission of alleles

\begin{tabular}{|c|c|c|c|c|c|}
\hline \multirow{3}{*}{ Variable } & \multirow{3}{*}{ N } & \multicolumn{4}{|c|}{ Effect size \pm s.e. } \\
\hline & & \multicolumn{2}{|c|}{ Between-family } & \multicolumn{2}{|c|}{ Within-family } \\
\hline & & Estimate & P-values & Estimate & P-values \\
\hline \multicolumn{6}{|l|}{ Non-Slavic } \\
\hline \multicolumn{6}{|c|}{-1606 A transmitted } \\
\hline LVMI $\left(\mathrm{g} \mathrm{m}^{-2}\right)$ & 217 & $+2.89 \pm 2.57$ & 0.26 & $-2.11 \pm 1.94$ & 0.28 \\
\hline LVID (mm) & 217 & $-1.93 \pm 0.68$ & 0.005 & $-0.55 \pm 0.50$ & 0.27 \\
\hline MWT (mm) & 217 & $+0.15 \pm 0.18$ & 0.42 & $-0.09 \pm 0.15$ & 0.53 \\
\hline \multicolumn{6}{|c|}{-962del transmitted } \\
\hline LVMI $\left(\mathrm{g} \mathrm{m}^{-2}\right)$ & 279 & $+1.62 \pm 1.67$ & 0.33 & $+1.87 \pm 1.44$ & 0.20 \\
\hline LVID (mm) & 279 & $+0.12 \pm 0.45$ & 0.79 & $-0.49 \pm 0.38$ & 0.19 \\
\hline MWT (mm) & 279 & $+0.12 \pm 0.12$ & 0.33 & $+0.24 \pm 0.11$ & 0.03 \\
\hline \multicolumn{6}{|l|}{ Slavic } \\
\hline \multicolumn{6}{|c|}{-1606 A transmitted } \\
\hline LVMI $\left(\mathrm{g} \mathrm{m}^{-2}\right)$ & 79 & $+0.48 \pm 3.04$ & 0.88 & $+2.63 \pm 3.03$ & 0.39 \\
\hline LVID (mm) & 79 & $-0.03 \pm 0.67$ & 0.96 & $+0.09 \pm 0.69$ & 0.89 \\
\hline MWT (mm) & 79 & $+0.08 \pm 0.20$ & 0.69 & $+0.21 \pm 0.21$ & 0.31 \\
\hline \multicolumn{6}{|c|}{-962del transmitted } \\
\hline LVMI $\left(\mathrm{g} \mathrm{m}^{-2}\right)$ & 110 & $-1.77 \pm 2.14$ & 0.41 & $-3.33 \pm 2.18$ & 0.13 \\
\hline LVID (mm) & 110 & $+0.40 \pm 0.48$ & 0.41 & $+0.36 \pm 0.49$ & 0.48 \\
\hline MWT (mm) & 110 & $-0.27 \pm 0.14$ & 0.055 & $-0.39 \pm 0.14$ & 0.007 \\
\hline
\end{tabular}

$N$ indicates the number of informative offspring. LVMI, LVID and MWT indicate left ventricular mass index, left ventricular end-diastolic internal diameter and mean wall thickness, respectively.

sion of the $-962 \mathrm{del}$ to Slavic offspring was associated with decreased MWT $(P=0.007)$.

\section{Sensitivity analyses}

Among non-Slavic participants, the 24-h urinary sodium excretion was lower in Hechtel-Eksel than in Mirano (169.7 vs. $184.8 \mathrm{mmol} \mathrm{day}^{-1} ; P=0.008$ ). Adding a genotype-by-sodium interaction term to the multivariable-adjusted mixed model enhanced the significance of the association between LVID and the G-1606A polymorphism (effect size in carriers of the $-1606 \mathrm{~A}$ allele, $-2.19 \mathrm{~mm} ; P=0.02)$. The interaction term was borderline significant $(P=0.07)$. It indicated that a $100 \mathrm{mmol} \mathrm{day}^{-1}$ higher sodium excretion was associated with a $0.57 \mathrm{~mm}$ increase in LVID in $-1606 \mathrm{~A}$ allele carriers, but with a $0.30 \mathrm{~mm}$ decrease in $-1606 \mathrm{GG}$ homozygotes.

Among 231 Slavic founders (Figure 2), $-1606 \mathrm{~A}$ allele carriers had higher LVMI (115.8 vs. $\left.107.4 \mathrm{~g} \mathrm{~m}^{-2} ; P=0.009\right)$ and higher MWT (11.6 vs. $11.1 \mathrm{~mm} ; P=0.005)$ than $-1606 G G$ homozygotes. Among 262 Slavic offspring, these phenotype-genotype associations were not significant. The multivariable-adjusted estimates $(-1606 \mathrm{~A}$ carriers $v s$. $-1606 G G$ homozygotes) were $87.8 v s .85 .8 \mathrm{~g} \mathrm{~m}^{-2}(P=0.37)$ for LVMI and 9.3 vs. $9.1 \mathrm{~mm}(P=0.20)$ for MWT.

Among Slavic founders, the -962ins/del genotype did not have any significant association with the left ventricular phenotypes; the multivariable-adjusted estimates (-962del carriers vs. -962ins homozygotes) were 110.6 vs. $108.8 \mathrm{~g} \mathrm{~m}^{-2}(P=0.51)$ for LVMI and $11.3 v s$. $11.2 \mathrm{~mm}(P=0.41)$ for MWT. In contrast, in Slavic offspring, $-962 \mathrm{del}$ carriers had lower LVMI (83.9 vs. $\left.87.4 \mathrm{~g} \mathrm{~m}^{-2} ; P=0.07\right)$ and MWT (8.8 vs. 9.3; $P=0.0003$ ) than -962 ins homozygotes (Figure 2 ).

\section{DISCUSSION}

The key finding of our study was that in multivariable-adjusted analyses, which also accounted for relatedness, LVMI and MWT were associated with genetic variation in the human $S A H$ gene. However, there was heterogeneity in the phenotype-genotype associations between non-Slavic and Slavic participants. Indeed, in nonSlavic participants, -962del carriers had higher LVMI and MWT than -962ins homozygotes. Transmission of the $-962 \mathrm{del}$ to non-Slavic offspring was also associated with higher MWT. In Slavic participants, -1606GG homozygotes had lower LVMI and lower MWT than $-1606 \mathrm{~A}$ carriers, but the latter association was confined to founders. Transmission of the $-962 \mathrm{del}$ allele to Slavic offspring was associated with lower MWT. These findings underscore that phenotype-genotype associations can only be reasonably investigated, while accounting for ecogenetic context. ${ }^{16,17}$

We stratified our analyses of the phenotype-genotype associations according to ethnicity, because of the differences between non-Slavic and Slavic subjects in LVMI, anthropometric characteristics, sodium excretion and the frequency of the -962ins/del genotypes. In earlier reports, we already noticed ethnic diversity between Italian and Slavic populations in the frequencies of the AGTR2 G1675A, ${ }^{11}$ ACE del/ins ${ }^{10}$ and $A G T C-532 T^{18}$ polymorphisms. In the latter study, ${ }^{18}$ Slavic compared with Italian subjects also had higher LVMI. Other investigators reported ethnic diversity between western European and Slavic populations in various genetic polymorphisms, ${ }^{19-21}$ which is probably due to differing genetic evolution along the migration patterns when Europe started to be populated from the Middle East and North Africa. ${ }^{22-24}$

Research into the $S A H$ gene found its roots in studies of genes, which are overexpressed in genetically hypertensive rats. ${ }^{1,25}$ The Suita population survey, ${ }^{6,26}$ and subsequent case-control studies $^{4,5,14}$ reported significant associations of hypertension and related phenotypes, such as obesity, hypercholesterolemia and hypertriglyceridemia, with genetic variation in the $S A H$ gene. Telgmann et al. ${ }^{14}$ identified five polymorphisms in the $S A H$ promoter region (C-1808T, G-1606A, -962ins/del, G-451A, T-67C), two polymorphisms in introns 5 and $7(C+9 / \operatorname{In} 5 T, A+20 / \operatorname{In} 7 T)$ and one non-functional missense variant $(K 359 N)$. In the PEGASE (Project d'Etude des Gènes de l'Hypertension Artérielle Sévère à Modérée Essentielle) case-control study for essential hypertension, Telgmann et al. ${ }^{14}$ reported association between obesity-related hypertension and the SAH G-1606A and -962ins/del polymorphisms. However, we recently analyzed blood pressure, measures of obesity, serum lipids and blood glucose as continuous phenotypes in 2603 relatives from 560 families and 31 unrelated subjects randomly recruited from six populations in the framework of the EPOCH. We also genotyped the $G-1606 A$ and -962ins/del polymorphisms. In spite of sufficient statistical power, none of the phenotype-genotype associations approached statistical significance. $^{\text {? }}$

Left ventricular mass index and MWT depend on a complex interaction between genetic and environmental factors, including lifestyle. They increase with both blood pressure and body mass index. This might explain why, in our current analyses, we were able to show the association of these left ventricular phenotypes with variation in the SAH gene, whereas our earlier study was negative. ${ }^{7}$ The PEGASE researchers ${ }^{14}$ reported that carriers of the $-1606 A$ allele had higher blood pressure and increased body mass index compared with $-1606 G G$ homozygotes. Blood pressure and body mass index increase with advancing age. This might explain, why in our Slavic participants the association of LVMI and MWT with the $G-1606 \mathrm{~A}$ 
G-1606A

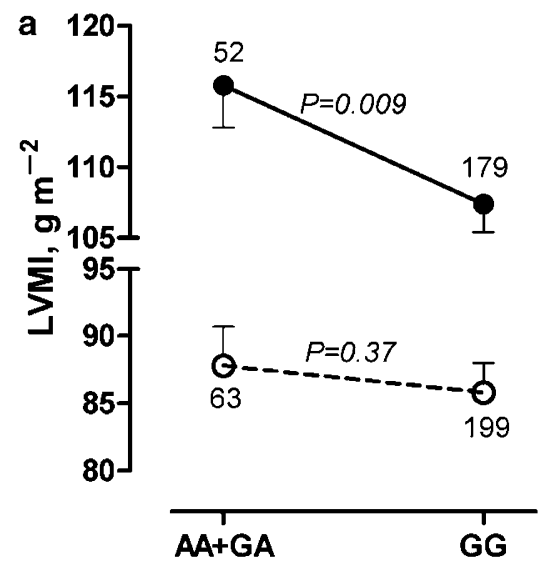

-962 ins/del

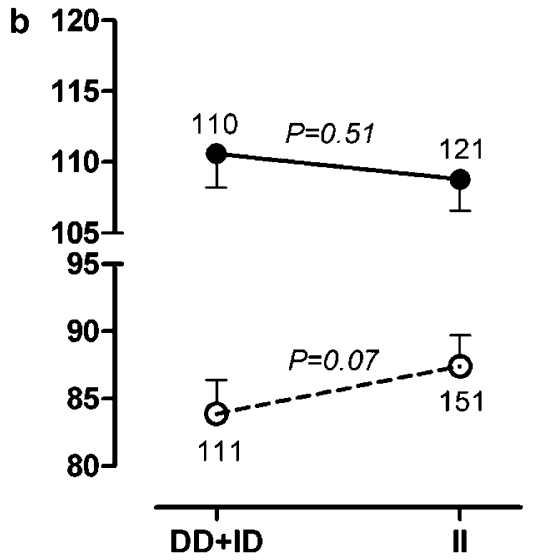

-962 ins/del

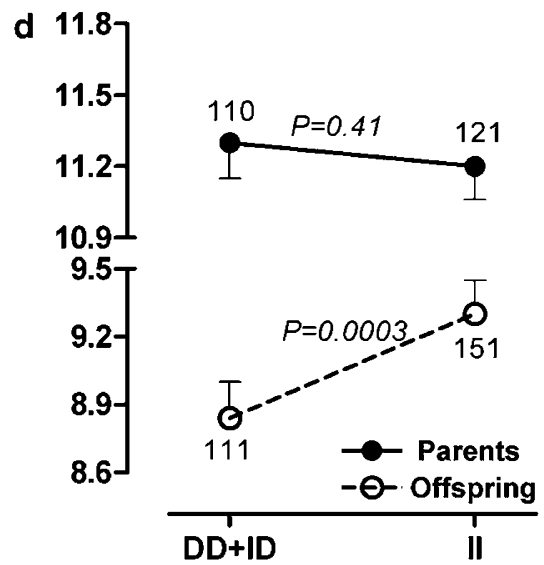

Figure 2 Left ventricular mass index (LVMI; (a and b)) and mean wall thickness (MWT; (c and d)) in relation to the G-1606A (a and c) and -962ins/del (b and d) polymorphisms in the human $S A H$ gene in Slavic parents and offspring. Values are means \pm standard error adjusted for relatedness, center, sex, age, systolic blood pressure, pulse rate, waist-to-hip ratio, use of antihypertensive drugs, smoking and alcohol intake in excess of 5 gday ${ }^{-1}$. MWT was additionally adjusted for body weight and height.

was confined to founders and why we did not pick it up in the familybased analysis of offspring.

In our analyses of non-Slavic subjects, we noticed that LVID was slightly greater in $-1606 G G$ than $-1606 \mathrm{~A}$ carriers. In the family-based analyses, the between-family component of phenotypic variation in LVID was significant, whereas the within-family component was not. The between-family component reflects population stratification or admixture, whereas the within-family component reflects the genetic effect and is robust against population substructure. The 24-h urinary sodium excretion was $15.1 \mathrm{mmol} \mathrm{day}^{-1}$ lower in Belgians than in Italians. Adding a genotype-by-sodium interaction term to the multivariable-adjusted mixed model enhanced the significance of the association between LVID and the G-1606A polymorphism. This interaction term was borderline significant. Thus, we suggest that the association in the non-Slavic participants between LVID and the G-1606A polymorphism might reflect population stratification, possibly explained by differences in sodium intake.

We observed complete linkage disequilibrium between $S A H$ G-1606A and -962ins/del polymorphisms. Using the PROC HAPLOTYPE procedure as implemented in the SAS package, version 9.1.3., we inferred three haplotypes: the combinations of $-1606 G$ with -962ins (59.6\%), $-1606 \mathrm{G}$ with $-962 \mathrm{del}$ (28.6\%) and $-1606 \mathrm{~A}$ with -962 ins $(11.9 \%)$. The combination of $-1606 \mathrm{~A}$ with $-962 \mathrm{del}$ did not exist. Studying the associations of the left ventricular phenotypes with the haplotypes did not produce any additional information, over and beyond the reported associations with single-nucleotide polymorphisms (data not shown).

Our study has to be interpreted within the context of its limitations. First, our sample size was relatively small and we only studied White Europeans of non-Slavic and Slavic origin. Our results might therefore not be generalizable to other ethnic groups. Second, LVM is a quantitative trait prone to measurement error. However, in each center only one experienced observer performed all ultrasound examinations. As reported elsewhere, ${ }^{18}$ the intra-observer intersession reproducibility coefficient, computed according to Bland and Altman's method, ${ }^{27}$ was less than $3 \%$ across centers. Third, the differences between genotypes in MWT and LVID were small. However, in the population-based analysis of the $G-1606 A$ polymorphism, the difference in LVMI was $5.8 \mathrm{~g} \mathrm{~m}^{-2}$. In the family-based analysis, the effect size associated with $-962 \mathrm{del}$ transmission was $3.33 \mathrm{~g} \mathrm{~m}^{-2}$. These estimates represent $41.4 \%$ and $23.8 \%$ of the first-year changes in LVMI on blood pressure-lowering treatment in the Losartan 
Intervention For Endpoint Reduction in Hypertension (LIFE) trial. $^{28}$

In conclusion, our population-based and family-based studies showed that LVMI and MWT, two phenotypes that are jointly influenced by blood pressure and obesity, might be related to the variation in the human $S A H$ gene. However, pending confirmation in other cohorts, the mechanisms underlying such association still need to be clarified in future research.

\section{ACKNOWLEDGEMENTS}

The Fonds voor Wetenschappeliik Onderzoek Vlaanderen, Ministry of the Flemish Community, Brussels, Belgium (Grants G.0424.03, G.0453.05 and G.0575.06), the University of Leuven, Belgium (Grants OT/00/25 and OT/05/ 49) gave support to the Studies Coordinating Centre in Leuven, Belgium. The European Union (Grants IC15-CT98-0329-EPOGH, LSHM-CT-2006-037093 InGenious HyperCare and HEALTH-F4-2007-201550 HyperGenes) supported the networked research in Kraków, Leuven, Novosibirsk, Padova and Maastricht. Stefan-Martin Brand-Herrmann was supported by an ICT in the FP7 ICT-2007-2 (no: 224635, 'VPH2'). Eva Brand was supported by a Heisenberg professorship from the Deutsche Forschungsgemeinschaft (Br1589/8-1). We gratefully acknowledge the expert technical assistance of Sandra Covens and Ya Zhu (Studies Coordinating Centre, University of Leuven, Belgium).

\section{DISCLOSURE/CONFLICT OF INTEREST}

None of the authors has a conflict of interest.

1 Iwai N, Inagami T. Expression of genes in the kidneys of hypertensive rats. Hypertension 1991; 17: 161-169.

2 Patel HR, Thiara AS, West KP, Lodwick D, Samani N. Increased expression of the SAH gene in the kidney of spontaneously hypertensive rats is localized to the proximal tubule. J Hypertens 1994; 12: 1347-1352.

3 Samani N, Whitmore SA, Kaiser MA, Harris J, See CG, Callen DF, Lodwick D. Chromosomal assignment of the human SA gene to 16p13.11. Biochem Biophys Res Comm 1994; 199: 862-868.

4 Benjafield AV, Iwai N, Ishikawa K, Wang WYS, Morris BJ. Overweight, but not hypertension, is associated with $S A H$ polymorphisms in Caucasians with hypertension. Hypertens Res 2003; 26: 591-595.

5 Haketa A, Soma M, Nakayama T, Sato M, Kosuge K, Aoi N, Matsumoto K. Two mediumchain acyl-coenzyme A synthase genes, SAH amd MACS1, are associated with plasma high-density lipoprotein cholesterol levels, but they are not associated with essential hypertension. J Hypertens 2004; 22: 1903-1907.

6 Iwai N, Katsuya T, Mannami T, Higaki J, Ogihara T, Kokame K, Ogata J, Baba S. Association betwen $\mathrm{SAH}$, an acyl-CoA synthetase gene, and hypertriglyceridemia, obesity and hypertension. Circulation 2002; 105: 41-47.

7 Tikhonoff V, Staessen JA, Kuznetsova T, Thijs L, Hasenkamp S, Bäumer V, Stolarz K, Seidlerová J, Filipovský J, Nikitin Y, Peleska J, Kawecka-Jaszcz K, Casiglia E, BrandHerrmann SM, Brand E, European Project On Genes in Hypertension (EPOGH) investigators. $\mathrm{SAH}$ gene variants revisited in the European Project on Genes in Hypertension. J Hypertens 2008; 26: 244-250.

8 Kuznetsova T, Staessen JA, Wang JG, Gasowski J, Nikitin Y, Ryabikov A, Fagard R. Antihypertensive treatment modulates the association between the D/l ACE gene polymorphism and left ventricular hypertrophy: a meta-analysis. J Hum Hypertens 2000; 14: 447-454.

9 41st World Medical Assembly. Declaration of Helsinki: recommendations guiding physicians in biomedical research involving human subjects. Bull Pan Am Health Organ 1990; 24: 606-609.

10 Kuznetsova T, Staessen JA, Stolarz K, Ryabikov A, Tikhonoff V, Olszanecka A, Bianch G, Brand E, Casiglia E, Dominiczak A, Fagard R, Malyutina S, Nikitin Y, KaweckaJaszcz K, European Project On Genes in Hypertension (EPOGH) Investigatorslpar. Relationship between left ventricular mass and the ACE D/l polymorphism varies according to sodium intake. J Hypertens 2004; 22: 287-295.
11 Kuznetsova T, Staessen JA, Thijs L, Kunath C, Olszanecka A, Ryabikov A, Tikhonoff V, Stolarz K, Bianchi G, Casiglia E, Fagard R, Brand-Herrmann SM, Kawecka-Jaszcz K, Malyutina S, Nikitin Y, Brand E, European Project On Genes in Hypertension (EPOGH) Investigators. Left ventricular mass in relation to genetic variation in angiotensin II receptors, renin system genes, and sodium excretion. Circulation 2004; 110: 2644-2650.

12 Gottdiener JS, Bednarz J, Devereux R, Gardin J, Klein A, Manning WJ, Morehead A, Kitzman D, Oh J, Quinones M, Schiller NB, Stein JH, Weissman NJ, American Society of Echocardiography. American Society of Echocardiography recommendations for use of echocardiography in clinical trials. A report from the American Society of Echocardiography's Guidelines and Standard Committee and the Task Force on Echocardiography in Clinical Trials. J Am Soc Echocardiogr 2004; 17: 1086-1119.

13 Staessen J, Bulpitt CJ, Fagard R, Joossens JV, Lijnen P, Amery A. Salt intake and blood pressure in the general population: a controlled intervention trial in two towns. J Hypertens 1988; 6: 965-973.

14 Telgmann R, Brand E, Nicaud V, Hagedorn C, Beining K, Schönfelder J, Brink-Spalink V, Schmidt-Petersen K, Matanis T, Vischer P, Nofer JR, Hasenkamp S, Plouin PF, Drouet L, Cambien F, Paul M, Tiret L, Brand-Herrmann SM. SAH gene variants are associated with obesity-related hypertension in Caucasians: the PEGASE Study. J Hypertens 2007; 25: 557-564.

15 Abecasis GR, Cardon LR, Cookson WOC. A general test of association for quantitative traits in nuclear families. Am J Hum Genet 2000; 66: 279-292.

16 Tikhonoff V, Kuznetsova T, Stolarz-Skrzypek K, Richart T, Kawecka-Jaszcz K, Casiglia E, Staessen JA. Modulation of genetic cardiovascular risk by age and lifestyle. Curr Cardiovasc Risk Rep 2008; 2: 398-404.

17 Kuznetsova T, Staessen JA, Brand E, Brand-Herrmann SM, Casiglia E, Filipovský J, Grodzicki T, Nikitin Y, Peleška J, Struijker-Boudier H, Bianchi G, Kawecka-Jaszcz K. Context-dependency of relations between cardiovascular phenotypes and genes involved in sodium homeostasis: findings from the European Project on Genes in Hypertension. Curr Hypertens Rev 2006; 2: 275-281.

18 Kuznetsova T, Staessen JA, Brand E, Brand-Herrmann SM, Casiglia E, Filipovský J, Grodzicki T, Nikitin Y, Peleška J, Struijker-Boudier H, Bianchi G, Kawecka-Jaszcz K. Context-dependency of relations between cardiovascular phenotypes and genes involved in sodium homeostasis: findings from the European Project on Genes in Hypertension. Curr Hypertens Rev 2006; 2: 275-281.

19 Tighe O, Dunican D, O'Neill C, Bertorelle G, Beattie D, Graham C, Zschocke J, Cali F, Romano V, Hrabincova E, Kozak L, Nechyporenko M, Livshits L, Guldberg P, Jurkowska M, Zekanowski C, Perez B, Desviat LR, Ugarte M, Kucinskas V, Knappskog P, Treacy E, Naughten E, Tyfield L, Byck S, Scriver CR, Mayne PD, Croke DT. Genetic diversity within the R408W phenylketonuria mutation lineages in Europe. Hum Mutat 2003; 21: 387-393.

20 Immel UD, Krawczak M, Udolph J, Richter A, Rodig H, Kleiber M, Klintschar M. Y-chromosomal STR haplotype analysis reveals surname-associated strata in the EastGerman population. Eur J Hum Genet 2006; 14: 577-582.

21 Rebala K, Mikulich AI, Tsybovsky IS, Siváková D, Dzupinková Z, Szczerkowska-Dobosz A, Szczerkowska Z. Y-STR variation among Slavs: evidence for the Slavic homeland in the middle Dnieper basin. J Hum Genet 2007; 52: 406-414.

22 Goldstein DB, Chikhi L. Human migrations and population structure: what we know and why it matters. Annu Rev Genomics Hum Genet 2002; 3: 129-152.

23 Mueller JC, Lõhmussaar E, Mägi R, Remm M, Bettecken T, Lichtner P, Biskup S, Illig T, Pfeufer A, Luedemann J, Schreiber S, Pramstaller P, Pichler I, Romeo G, Gaddi A, Testa A, Wichmann HE, Metspalu A, Meitinger T. Linkage disequilibrium patterns and tagSNP transferability among European populations. Am J Hum Genet 2005; 76: 387-398.

24 Pericic M, Lauc LB, Klariæ IM, Rootsi S, Janiæijevic B, Rudan I, Terzic R, Colak I, Kvesic A, Popovic D, Sijacki A, Behluli I, Dordevic D, Efremovska L, Bajec DD, Stefanoviæ BD, Villems R, Rudan P. High-resolution phylogenetic analysis of southerastern Europe traces major episodes of paternal gene flow among Slavic populations. Mol Biol Evol 2005; 22: 1964-1975.

25 Okuda T, Sumiya T, Muzutani K, Tago N, Miyata T, Tanabe T, Kato H, Katsuya T, Higaki J, Ogihara T, Tsujita Y, Iwai N. Analyses of differential gene expression in genetic hypertensive rats by microarray. Hypertens Res 2002; 25: 249-255.

26 Iwai N, Mannami T, Tomoike H, Ono K, Iwanaga Y. An Acyl-CoA synthetase gene family in chromosome 16p12 may contribute to multiple risk factors. Hypertension 2003; 41: 1041-1046.

27 Bland JM, Altman DG. Statistical methods for assessing agreement between two methods of clinical measurement. Lancet 1986; 1: 307-310.

28 Devereux RB, Wachtell K, Gerdts E, Boman K, Nieminen MS, Papademetriou V, Rokkedal J, Harris K, Aurup P, Dahlöf B. Prognostic significance of left ventricular mass change during treatment of hypertension. JAMA 2004; 292: 2350-2356. 